\title{
Sculpt plaster therapy for abdominal circumference reduction
}

\section{Sara Gonçalves}

\author{
Clínica Áurea - Aesthetic Biomedicine Clinic; Rua de Três Lagares, bloco 1, loja G, 5000-577 Vila Real, Portugal \\ Corresponding author: Sara Gonçalves, MSc, E-mail: sgoncalves@utad.pt
}

Sir,

Research demonstrates that the pattern of one's fat distribution has a profound impact on cardiometabolic risk [1].

Sculpt plaster therapy is a beauty treatment that allows quick elimination or reduction of cellulite, flaccid skin, and localized fat. Plaster helps to eliminate liquid from the body, producing improvements that are not only aesthetic in nature but also health-wise, for instance, by maximizing abdominal fat loss.

In practice, the procedure begins with the preparation of the skin. During the preparation process, the area is cleansed and exfoliated for better absorption of the ingredients. During the treatment, the plaster absorbs heat released by the body, which increases blood circulation and facilitates the penetration of the active ingredients into the skin.

To complement sculpt plaster therapy, green clay has also been used. Green clay contains minerals such as iron and magnesium, which facilitate lipolysis. Iron increases the rate of lipolysis in adipocytes [2]. Magnesium is gathered by adipocytes during lipolysis [3].

The purpose of this study was to analyze the effect of sculpt plaster therapy in the reduction of abdominal circumference.

The initial consultations and subsequent treatments were developed in Clínica Áurea (Aesthetic Biomedicine Clinic, Portugal). A total of nine patients were submitted to the treatment. During the initial consultation, all the procedures, side effects, expected results, and contraindications were explained. The patients signed an informed consent. Also, during the initial consultation, initial measurements were taken. The aim of this procedure was to measure the reduction in abdominal circumference.

\section{Instruments}

A nonstretchable measuring tape was used to measure height and circumference. Tanita UM-076 with bioelectrical impedance was used to measure weight, muscle mass, and fat mass.

The following components were used: green clay (from lot 00301, Seara, Portugal, smectite clay with the following chemical composition: $\mathrm{SiO}_{2}(27.8 \%)$, $\mathrm{CaO}(25.5 \%), \mathrm{Al}_{2} \mathrm{O}_{3}(11.2 \%), \mathrm{MgO}(4.6 \%), \mathrm{Fe}_{2} \mathrm{O}_{3}$ (2.3\%), $\mathrm{K}_{2} \mathrm{O}(1.57 \%), \mathrm{TiO}_{2}(0.37 \%), \mathrm{Na}_{2} \mathrm{O}(0.05 \%)$; loss on ignition (26.0\%)), magnesium sulfate, distilled water, Exfoliating Cherry and Nutshell Gel (Paraíso, Portugal), plastic film, sculpt plaster (from lot 010824, Body Secrets by SB Nails: calcium sulfate, bentonite, vanillin, ascorbic acid, and $\mathrm{Cl}$ 77007), and massage oil (Quickepil, Portugal).

\section{Procedures}

The treatments were applied once a week for five weeks. With every session, the patients' measurements were collected. Abdominal circumference was measured by finding the middle point between the last rib cage and the iliac crest. Height, fat mass, muscle mass, and weight were also measured.

During the first session, green clay therapy was given. Green clay was prepared with the following components: $30 \mathrm{~g}$ of green clay, $30 \mathrm{~g}$ of magnesium sulfate, and $50 \mathrm{~mL}$ of distilled water. The components 
were mixed and then applied. The patients were wrapped with a plastic film in the abdominal region for twenty minutes. Green clay was removed with water.

During sessions two to five, sculpt plaster therapy was given. The abdominal area was exfoliated with an exfoliating gel. The patients were wrapped in a plastic film for fifteen minutes. Afterward, the exfoliating gel was removed with water. Sculpt plaster was prepared with the following components: $30 \mathrm{~g}$ of sculpt plaster and $30 \mathrm{~g}$ of distilled water. The components were mixed and applied in the abdominal area. The patients were wrapped in bandages and a plastic film to keep the area moist and to maintain body temperature for fifty-five minutes. After this, the sculpt plaster was removed with water and shaping massage with a massage oil was given for thirty minutes.

Table 1 shows a decrease in abdominal circumference, weight, and fat mass and an increase in muscle mass (Fig. 1).

The results of sculpt plaster therapy are due to the individual action of each of the components

Table 1: The means of weight, fat mass, and abdominal circumference loss and muscle mass gain

\begin{tabular}{ccccc}
\hline $\begin{array}{c}\text { Weight } \\
(\mathbf{k g})\end{array}$ & $\begin{array}{c}\text { Fat mass } \\
(\%)\end{array}$ & $\begin{array}{c}\text { Abdominal } \\
\text { circumference (cm) }\end{array}$ & $\begin{array}{c}\text { Muscle } \\
\text { mass (kg) }\end{array}$ \\
\hline Mean & $-0,24$ & $-1,13$ & $-3,59$ & $+0,54$ \\
\hline
\end{tabular}

after topical application. Magnesium is gathered by adipocytes during lipolysis and, as fatty acids are mobilized, its concentration decreases. This is the reason why the administration of sculpt plaster therapy may intensify the lipolysis process. There is, nonetheless, a lack of studies on the action of these components through topical absorption.

Taking into account the results of this study, it seems that sculpt plaster therapy may enhance the reduction in abdominal circumference $[4,5]$. It should, however, be a complement to physical exercise and an optimal diet [6]. One study shows that complement sculpt plaster therapy coupled with aerobic exercise reduces abdominal fat [2].

Further investigation could be conducted in order to study the influence of temperature increase, abdominal lymphatic drainage, differences between sculpt plaster in powder-as used in this study and plaster bandage, and the type of exercise performed while using the sculpt plaster. Separate studies should be conducted to better understand each of the factors.

It would also be meaningful to study the effects of sculpt plaster therapy in the gluteal-femoral area, especially in females, as, in females, fat deposits are located preferentially in this region $[5,7]$.

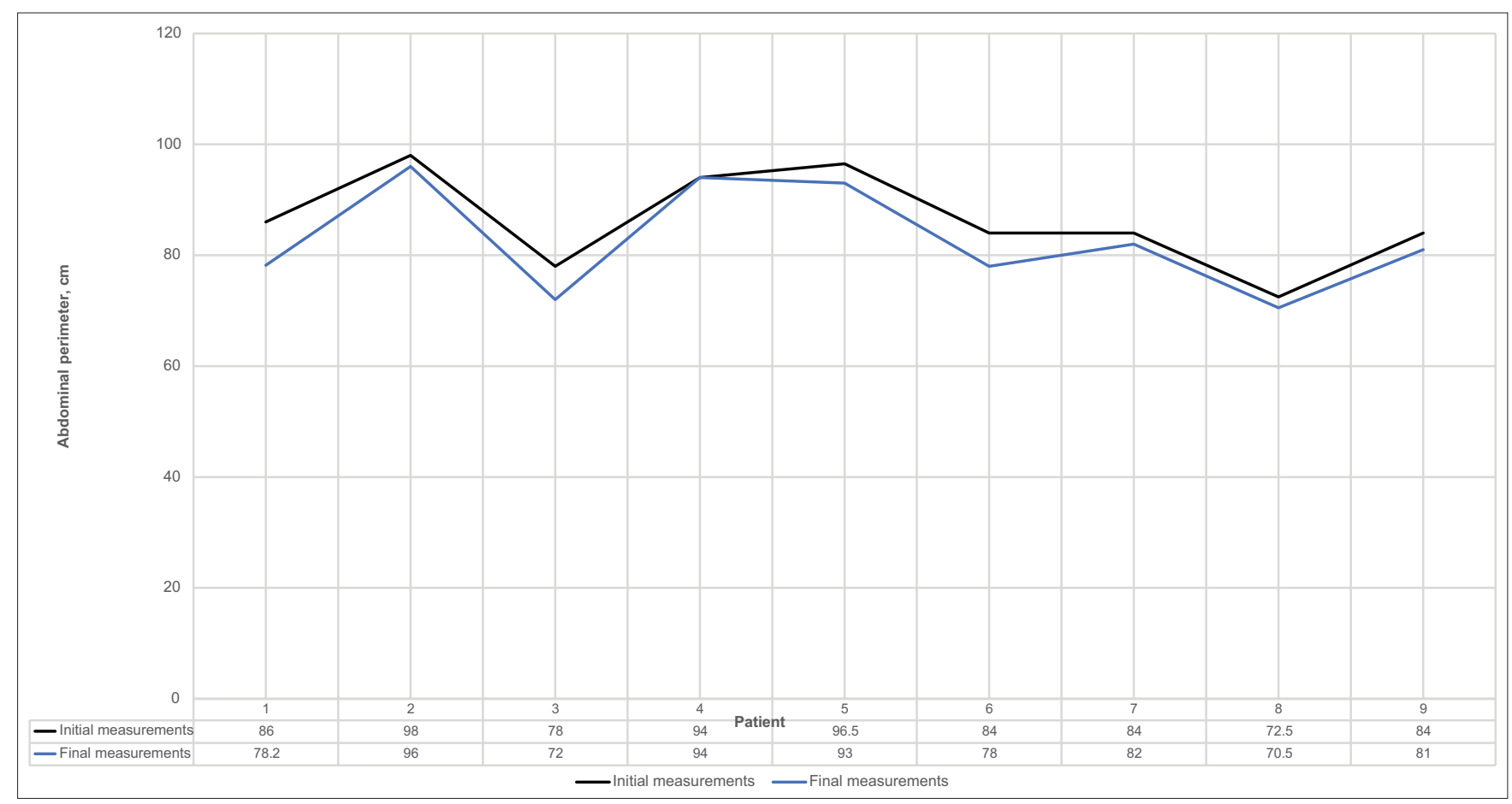

Figure 1: Initial and final abdominal circumference measurements. 
It is important to highlight the results of this study so that aesthetic biomedicine professionals consider this novel tool for lipolysis enhancement.

\section{Consent}

The examination of the patient was conducted according to the principles of the Declaration of Helsinki.

\section{REFERENCES}

1. Amato MC, Guarnotta V, Giordano C. Body composition assessment for the definition of cardiometabolic risk. J Endocrinol Invest. 2013;36:537-43.

2. Santos Moreira J, Melo ASCP, Noites A, Couto MF, Melo CA, Adubeiro NCFA. Plaster body wrap: Effects on abdominal fat. Integr Med Res. 2013;2:151-6.

3. Laudańska H, Lemancewicz A, Kretowska M, Reduta T, Laudański T. Permeability of human skin to selected anions and cations--in vitro studies. Res Commun Mol Pathol Pharmacol.
2002;112:16-26.

4. Ingemann-Hansen T, Halkjaer-Kristensen J. Lean and fat component of the human thigh. The effects of immobilization in plaster and subsequent physical training. Scand J Rehabil Med. 1977;9:67-72.

5. Song Q, Yuan Y, Jiao C, Zhu X. Curative effect of Tai Chi exercise in combination with auricular plaster therapy on improving obesity patient with secondary hyperlipidemia. Int J Clin Exp Med. 2015;8:21386-92.

6. Gonçalves S. Elaboration and subsequent application of a protocol for measure reduction in a patient with Hashimoto thyroiditis. Our Dermatol Online. 2020;11:243-6.

7. Vogel MAA, Wang P, Bouwman FG, Hoebers N, Blaak EE, Renes J, et al. A comparison between the abdominal and femoral adipose tissue proteome of overweight and obese women. Sci Rep. 2019;9:4202.

Copyright by Sara Gonçalves. This is an open-access article distributed under the terms of the Creative Commons Attribution License, which permits unrestricted use, distribution, and reproduction in any medium, provided the original author and source are credited.

Source of Support: Nil, Conflict of Interest: None declared. 